\title{
Use of High Resolution Satellite Images for the Calibration of Hydro-geological Models in Semi-Arid Regions: A Case Study
}

\author{
Gerardo Di Martino, Antonio Iodice, D Riccio, \\ Giuseppe Ruello, Ivana Zinno \\ DIBET, University of Napoli "Federico II" \\ Napoli, Italy \\ ruello@,unina.it
}

\author{
Youssouf Koussoube \\ University of Ouagadougou \\ Ouagadougou, Burkina Faso \\ youssouf.koussoube@univ-ouaga.bf
}

\begin{abstract}
In this paper we present the preliminary results of a project devoted to use hydrologic and remote sensing models and data for water resource management in semi-arid regions. The project is developed in the Sahel region of Burkina Faso, where a set of high resolution synthetic aperture radar (SAR) images was acquired. The rationale of the project along with the preliminary results obtained by the processing of high resolution CosmoSkyMed data are presented and discussed.
\end{abstract}

Keywords- Semi-arid regions - water management-Synthetic Aperture Radar

\section{INTRODUCTION}

In this paper we present the rationale and the preliminary results of a research project devoted to the appropriate and innovative use of remotely sensed data for water monitoring in semi-arid regions.

In particular, the project is focused on the northern area of Burkina Faso, in the sub-Saharan region of West Africa. The country is one of the poorest in Africa, with a climate characterized by the alternation of rainy ( 3 months) and dry ( 9 months) seasons.

Such a climate provoke agricultural problems for the occurrence of floods in the rainy season and intense drought in the dry season. The identification, storage and distribution of water resources are crucial problems for the improvement of the local people standard of living. The use of remotely sensed data can be very important, because it can give a synoptic view of the country, and it provides a support for the above cited activities.

The idea behind the project is to use hydro-geological, remote sensing models and GIS techniques for water resource monitoring. In particular, we use Cosmo-SkyMed data obtained in the frame of a research project approved by the Italian Space Agency (ASI). A set of strip-map, spotlight and scan-sar data is provided from April 2010 to March 2012.

\author{
Fabio Ciervo, Maria Nicolina Papa \\ University of Salerno \\ Salerno, Italy \\ mnpapa@unisa.it
}

The acquired data is starting to be processed, so we can here present the first results. At the moment, we acquired seven strip-map data and an interferometric couple, for extracting topographical characteristics.

In Section II we present the project rationale, with a description of the case study area and the main hydrologic and electromagnetic models that will be employed for exploiting the data. Section III is devoted to a presentation of the COSMO-SkyMed mission and the first available data. In Section IV the techniques developed and the preliminary results will be described. A discussion on the project potentiality and on the future developments is provided in the conclusions section.

\section{Project Rationale}

\section{A. The srudied area}

Burkina Faso is a continental country located in West Africa more than $1000 \mathrm{~km}$ from the Gulf of Guinea. It has approximately 14 milion people [1]. Almost $80 \%$ of the population live in rural areas depending from agriculture and livestock.

Burkina Faso is a Sahelian country characterized by strong inter-annual variability of rainfall. The last years of the 20th century (from 1970 to 2000) were marked by a long period of drought. A return to normal rainfall rates is experienced since the beginning of the 2000s [2] when the average rainfall ranges from $350 \mathrm{~mm}$ per year in the North to $1200 \mathrm{~mm}$ per year in the South of the country, according to a latitudinal gradient [3]. The annual rainfall is not uniformly distributed, with a rainy season from May to September and dry season from October to April. These precipitations come from the Gulf of Guinea air moisture (monsoon). Rapid regime of rainy event causes a crusting of the soil and a significant runoff. The air temperature varies with a maximum monthly average of $41^{\circ} \mathrm{C}$ (March April) and a minimum monthly average of $17^{\circ} \mathrm{C}$ (December - 
January) for the period 1965-2006. The evaporation is about $2000 \mathrm{~mm}$ per year so that at the end of the dry season only the surface water bodies with more than $3 \mathrm{~m}$ of height survive.

The long drought period and some inadequate cultivation practices resulted in a degradation of land and a high runoff. The infiltration of water is so limited.

This climatic situation of Burkina Faso shows the need for a better management of water resources for agricultural needs and drinking water supply.

\section{B. Hydrological Modeling}

In the above presented context land-use and water resource management choices have a prominent role in order to minimize the effects of the extreme climate conditions. Any management policy that could interfere with the local climate balance needs a hydrological assessment to calibrate and to forecast the future effects. Territorial management and hydrologic modeling studies are intrinsically related to the spatial processes of the hydrologic cycle-system. A multitude of ways to classify rainfall-runoff models from deterministic to stochastic models, from physically-based to empirical and conceptual models, and the most distinctive, from lumped models to distributed models, exists to reproduce the complex nature of hydrologic processes determined by a number of highly interconnected water, energy and vegetation processes at various spatial scales [4]-[5]. In this regard the deep knowledge of the problem requires an integrated approach of the geographical information. Significant efforts have been made in the linkage of geographic information systems (GIS) and hydrological-models [6] improving great bulk data management and rapid parameter estimation tools.

The overriding need, in the choice of the proper hydrological model, has been the possibility of a widespread diffusion of the tools, developed in the framework of the present work, between local Burkinabè users. This consideration drove the choice to software freely available to the public.

The SWAT (Soil and Water Assessment Tool) model [8], developed by the USDA (Agricultural Research Service at the Grassland, Soil and Water Research Laboratory in Temple, Texas, USA) has been selected for these applications, because it holds all the requested features. The code intends to be a model that provides a direct support to the management decisions. Many physical processes could be modeled by SWAT (weather, hydrology, stream routing, sedimentation, crop growth, nutrients, pesticide, etc.). In this work pollutant processes are not considered and only physical observables inherent to the hydrologic balance (water resources, flood, erosion) will be included. The land phase of the hydrologic processes, the driving force behind the movement of sediments, nutrients or pesticides, is simulated by the model based on the following water balance equation:

$$
\mathrm{SW}_{\mathrm{t}}=\mathrm{SW}_{\mathrm{o}}+\sum_{\mathrm{i}=1}^{\mathrm{t}}\left(\mathrm{R}_{\text {day }}-\mathrm{Q}_{\text {surf }}-\mathrm{E}_{\mathrm{a}}-\mathrm{W}_{\text {seep }}-\mathrm{Q}_{\mathrm{gw}}\right)
$$

where, $\mathrm{SW}_{\mathrm{t}}(\mathrm{mm})$ is the final soil water content, $\mathrm{SW}_{\mathrm{o}}$ is the initial soil water content, $t$ is the time (days), $R_{\text {day }}$ is the amount of precipitation, $Q_{\text {surf }}$ is the amount of surface runoff, $E_{a}$ is the amount of evapotranspiration, $W_{\text {seep }}$ is the amount of water entering the vadose zone from the soil profile, and $\mathrm{Q}_{\mathrm{gw}}$ is the amount of return flow on day $\mathrm{i}(\mathrm{mm})$.

For the ET parameter SWAT provides different methods assessment. The runoff evaluation is approached basing on curve number method and Green \& Ampt infiltration equation. Percolation is modeled with a layered storage routing technique combined with a crack flow model. Loadings of flow from the upland areas to the main channel are routed through the stream network of the watershed using a process similar to HYMO. The SWAT also implements a Modified Universal Soil Loss Equation (MUSLE) for simulating soil erosion.

The complexity of the simulated physical processes requires a great number of data. The hydro-morphological basin analysis requires the knowledge of topographical information, soil moisture, land cover and land use and so on. Most of this data can efficiently be acquired via remote sensing instruments, with a huge economic saving.

\section{Remote sensing}

The use of SAR images for hydrological applications is often limited by the difficulty of extracting physical information from the speckled data. In this paper we present innovative models for the retrieving of information from SAR images, based on efficient and innovative algorithms for the image interpretation. The results of the models are used as a starting point for the development of techniques of production of value added information.

In particular, we provide the image interpreter the chance to use simple relations between the image characteristics and the geometric and dielectric parameters of the observed surfaces.

The innovative character of the proposed method is the intensive use of fractal models. It requires the development of new models for the electromagnetic scattering from fractal surfaces [7]. In this paper we focus the attention mainly on two applications: the retrieval of topographic information via interferometric classical techniques and the classification of the images by means of innovative fractal tools [8]. The details on the techniques are provided along with the preliminary results in Section IV.

\section{COSMO-SKYMED DATA}

Cosmo-SkyMed is one of the most advanced SAR missions in orbit around our planet. It allows the acquisition of SAR images at $\mathrm{X}$ band with a resolution of the order of the meter. So far, 9 strip-map images have been acquired in the region of interest in the frame of the project. In this Section we present some sample of the data acquired in the region of interest. The image cover an area of about $40 \mathrm{~km} \mathrm{x} 40 \mathrm{~km}$, near the city of Ouahigouya, capital of the Yatenga district, in the North of Burkina Faso. In Figure 1 we show the SAR image acquired on the $14^{\text {th }}$ of July, 2010, in order to evidence some of the characteristics that are worth to be noted. In the bottom left corner the artificial lake that feeds the city of Ouahigouya is 
visible. In the bottom right corner another big area (called the Tougou basin) flooded by a dam is easily recognized.

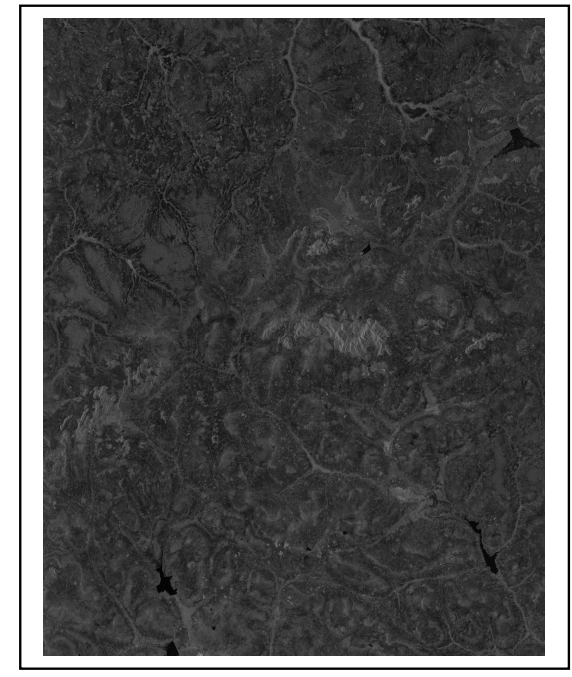

Figure 1. Example of an acquired stripmap Cosmo SkyMed image of the OuahigouYa area. The original image resolution is $3 \mathrm{~m} \times 3 \mathrm{~m}$; the pixel spacing is $1.22 \mathrm{~m} \mathrm{x} 1.9 \mathrm{~m}$. The images were then averaged by a $8 \times 8$ factor. A further average is due to the image compression

The area is crossed from the upper right corner to the city of Ouahigouya by the the watershed that separates the Black and the White Volta basins. In order to appreciate the image full resolution, in Figure 2 we show a spotlight image of the North-West part of the observed area.

Figure 2 shows that the SAR image present a detail that allows to distinguish objects of the size of the trees. This variety of details is absolutely new for data acquired from satellites, and its characterization is still object of scientific discussion. The data carries physical information on the area topography, morphology and on physical parameters of interest in agriculture. In the next Section, we present innovative techniques for extracting part of this information.

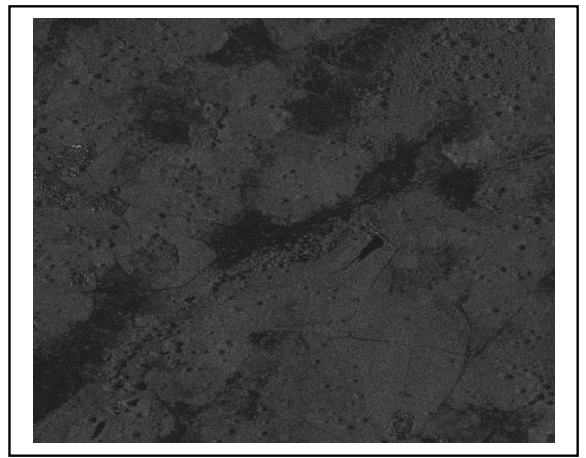

Figure 2. Detail of the Bidi area dam. The pixel spacing is $1.22 \mathrm{~m} \times 1.9 \mathrm{~m}$.

\section{PRELIMINARY RESULTS}

At the actual state of the project, 9 strip-map SAR images have been acquired and a complete processing chain is in progress, in order to retrieve as much information as possible. In this Section we limit our attention on two examples: the topography extraction, which is performed via classical techniques, but that represent a strong value added for hydrogeological modeling; and an innovative fractal technique for classifying SAR images. The details are provided in the following.

\section{A. Topographic information}

A couple of SAR images were acquired at the beginning of June, 2010, with a temporal separation of 1 day. Such a couple allowed the extraction of a digital elevation model (DEM) that was used to extract the main topographic information.

Thank to the limited temporal shift and to the absence of significant vegetation at the beginning of the rainy season, the interferometric coherence, presented in Figure 3 is very high in most of the observed area. Some topographic characteristics can be already identified in the coherence information. The river streams can be noted as the dark, non coherent areas. Some villages, not easily visible in the intensity image, can be identified as bright spots.

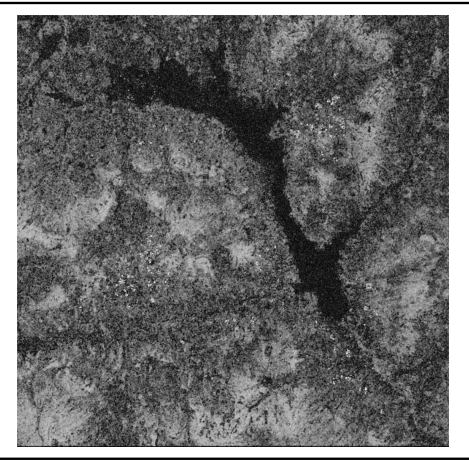

Figure 3. Interferometric coherence in the Tougou basin area.

A complete interferometric chain was implemented via standard techniques. In Figure 4 and 5 the interferometric phase (after flat Earth removal) and the obtained georeferenced DEM are presented, respectively.

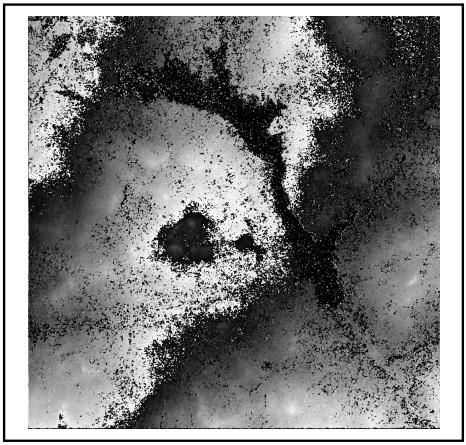

Figure 4. Interferometric coherence in the Tougou basin area. 


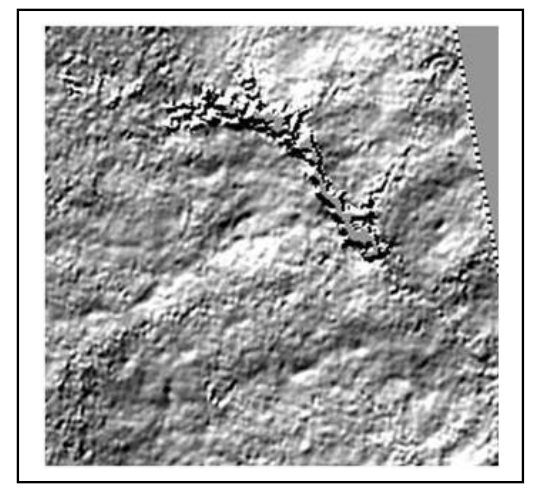

Figure 5. Georeferenced digital elevation model of the Tougou area.

The data presented in Figure 5 represent a first $30 \mathrm{~m}$ x $30 \mathrm{~m}$ digital elevation model of the observed area. A complete error budget analysis is still in the implementation phase. A measurement campaign is also planned, so that we expect that we could discuss its results during the conference presentation.

\section{B. Innovative fractal classification detection study}

One of the innovative characteristics of the whole project is the implementation of fractal models in the data analysis. Fractal models are widely accepted as the most suitable geometrical models for accounting for the irregularities of natural surfaces. In particular, for the surface description we use the fractional Brownian motion $(\mathrm{fBm})$, which is a continuous everywhere, differentiable nowhere process, described in terms of its increment pdf. A stochastic process $z(x, y)$ is an $\mathrm{fBm}$ surface if, for every $x, y, x^{\prime}, y^{\prime}$, it satisfies the following relation:

$\operatorname{Pr}\left\{z(x, y)-z\left(x^{\prime}, y^{\prime}\right)<\bar{\zeta}\right\}=\frac{1}{\sqrt{2 \pi} s \tau^{H}} \int_{-\infty}^{\bar{\zeta}} \exp \left(-\frac{\zeta^{2}}{2 s^{2} \tau^{2 H}}\right) d \zeta$

where $\tau$ is the distance between the points $(x, y)$ and $\left(x^{\prime}, y^{\prime}\right), \operatorname{Pr}$ stands for "probability" and the two parameters that control the $\mathrm{fBm}$ are:

- $\quad H$ : the Hurst coefficient $(0<H<1)$, related to the fractal dimension $\mathrm{D}$ via the relation $D=3-H$.

- $\quad s$ : the standard deviation, measured in $\left[\mathrm{m}^{1-\mathrm{H}}\right]$, of surface increments at unitary distance.

It has been demonstrated [8] that an isotropic $\mathrm{fBm}$ exhibits a power law spectrum $\mathrm{S}_{f B m}(\mathrm{k})$ :

$$
S_{f B m}(k)=S_{0} k^{-\alpha}
$$

wherein the spectral and spatial domain parameters are related [4] by the following relations:

$$
\begin{gathered}
\alpha=2+2 H=8-2 D, \\
S_{0}=s^{2} 2^{2 H} 2 \pi H \frac{\Gamma(1+H)}{1-H},
\end{gathered}
$$

$\Gamma$ being the Gamma function. Note that from the inequalities $0<H<1$ we get the range of allowed values for the spectral slope: $2<\alpha<4$. In a recent paper [9] it was demonstrated tha, under the assumption of validity of the small perturbation method, the SAR image spectrum $\mathrm{S}_{\text {imm }}$, in determined spectral intervals can be also written as a power law :

$$
S_{i m m}(k)=S_{0}^{i m m} k^{-\alpha_{i m m}} .
$$

Such a relation is very useful for fractal parameter estimation purposes, because in Log-Log scale it represent a linear relation. Therefore, a linear regression allows to evaluate the slope, which is related with the fractal dimension. In Figure 6 we show the intensity image considered as a case study. It is relative to the area of the city of Ouahigouya, and it is characterized by the presence of vegetated areas (most of the bright pixels), bare soils (most of the grey pixels), water (the black pixels) and urban areas (bright pixels at the bottom of the presented image).

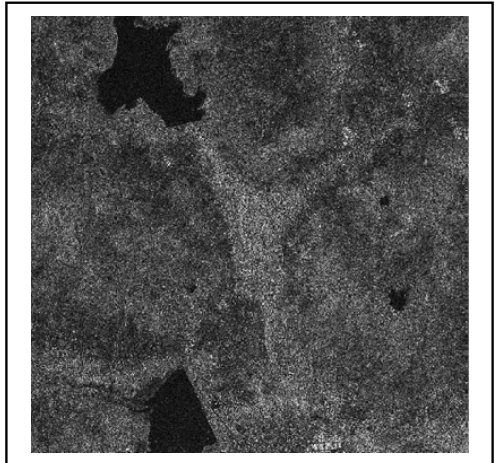

Figure 6. Georeferenced digital elevation model of the Tougou area.

The use of relation (6) allows to evaluate the fractal parameters on the image, with the implementation of a sliding window that examines the whole image. Maps of fractal dimension and of the standard deviation at unitary distance were obtained and their conjunct evaluation led to the classification map presented in Figure 7. Despite a ground truth is still not available, the obtained results appears in perfect agreement with the information known on the land under observation.

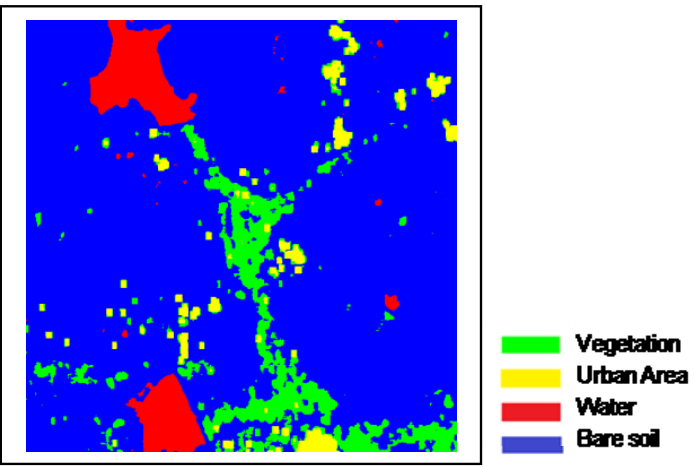

Figure 7. Georeferenced digital elevation model of the Tougou area. 


\section{CONCLUSIONS}

In this paper we presented the rationale and the preliminary results of a project devoted to use high reolution COSMOSkyMed data for calibrating hydrological models. The hydrological model, as well as most of the remote sensing processing, was developed with open source instruments, in order to guarantee the availability at almost no cost of the final results to the final users.

In particular, we presented the preliminary results relative to the extraction of topographic information and an innovative classification fractal technique. The obtained results encourage to follow the idea that the new high resolution SAR data can provide an innovative and powerful instrument for monitoring developing countries at a limited cost with a benefit for the living condition of local people.

\section{ACKNOWLEDGMENT}

This work was supported by the Italian Space Agency, that provided the data in the frame of the project ID 2218 of the first COSMO-SkyMed Announcement of Proposal.

\section{REFERENCES}

[1] Institut national de la statistique et de la démographie du Burkina Faso (INSD), Recensement général de la population du Burkina Faso, 2006.

[2] Balme M., Lebel T., Amani A, "Années sèches et années humides au Sahel : quo vadimus?”, Hydrol. Sci. J., 51(2), 254-271, . (2006).

[3] Koussoubé Y. 2010, “ Hydrogéologie des séries sédimentaires de la dépression piézométrique du Gondo, (Bassin du Sourou) - Burkina Faso / Mali", Thèse de Doctorat, UPMC Sorbonne Universités, 2010.

[4] Beven, K. J. ,'Distributed models', in Anderson, M. G. and Burt, T. P. (Eds ), 1985.

[5] Refsgaard, Terminology, modelling protocol and classification of hydrological model codes. In: Abbott, M.B., Refsgaard, J.C. (Eds.), 1996.

[6] Springer, D.,"Towards integrating GIS Modelling and Software”, pp. 451-459, 2000

[7] Franceschetti G. and Riccio D., Scattering, Natural Surfaces and Fractals, Elsevier, 2006.

[8] G. Di Martino, A. Iodice, D. Riccio, G. Ruello, "A Novel Approach for Disaster Monitoring: Fractal Models and Tools", IEEE Geosci. Remote Sens., vol. 45, pp. 1559-1570, 2007.

[9] Di Martino G., Iodice A., Riccio D., Ruello, G., "Imaging of Fractal Profiles", IEEE Geosci. Remote Sens., vol. 48, pp.3280-3289, 2010. 